\title{
Prevalence of risk phenotypes associated with rs2285666 single nucleotide polymorphism of ACE2 in the world population susceptible to SARS-CoV-2 infection
}

\author{
Mohitosh Biswas ${ }^{1}$ \\ ${ }^{1}$ University of Rajshahi
}

July 8, 2020

\begin{abstract}
Aims: Variability of ACE2 expression encoded by the ACE2 gene may be important for susceptibility and clinical outcomes of SARS-CoV-2 infection. This study was aimed to identify potential single nucleotide polymorphisms (SNPs) of ACE2 relevant to SARS-CoV-2 infection and predictively assigned risk phenotypes. Methods: Literature was searched in different databases to identify the SNPs of ACE2 that may regulate ACE2 expression in different human tissues relevant to either SARS-CoV-2 or SARS-CoV infection. Allele and genotype information of rs2285666 SNP of ACE2 was obtained from the 1000 Genomes project Phase III in line with Fort Lauderdale principles and phenotypes were assigned accordingly based on carrying characteristics ACE2 allele. Results: About 16 SNPs of ACE2 as potential venture for susceptibility to SARS-CoV-2 infection was identified from the literature. Predicted high-risk phenotypes of ACE2 expressor due to carrying rs2285666 SNP of ACE2 was highly prevalent in East Asia (40.7\%; 95\% CI 36\%-45\%), followed by South Asia (36.8\%; 95\% CI 33\%-41\%), America (22.8\%; 95\% CI $18 \%-27 \%)$, Europe (14.5\%; 95\% CI 11\%-18\%) and Africa (12.3\%; 95\% CI 10\%-15\%), respectively. In total, $\sim 25 \%$ of the world population participated in the 1000 Genomes project was predictively identified as being at high-risk for SARS-CoV-2 infection due to carrying rs2285666 ACE2 genetic polymorphism. Conclusion: Identification of high-risk phenotypes for SARS-CoV-2 infection through screening of ACE2 genetic polymorphisms may be valuable for SARS-CoV-2-related COVID-19 prevention and treatment in the population. Customized DNA microarray techniques or next generation sequencing may holistically advance this newly evolving research area of infection genetics.
\end{abstract}

\section{Hosted file}

Biswas M_ACE2_SARS-CoV-2 infection.docx available at https://authorea.com/users/338169/ articles/468039-prevalence-of-risk-phenotypes-associated-with-rs2285666-singlenucleotide-polymorphism-of-ace2-in-the-world-population-susceptible-to-sars-cov-2infection

\section{Hosted file}

Figures.docx available at https://authorea.com/users/338169/articles/468039-prevalence-ofrisk-phenotypes-associated-with-rs2285666-single-nucleotide-polymorphism-of-ace2-in-theworld-population-susceptible-to-sars-cov-2-infection 